\title{
Aeromonas popoffii sp. nov., a Mesophilic Bacterium Isolated from Drinking Water Production Plants and Reservoirs
}

\author{
GEERT HUYS, ${ }^{1 *}$ PETER KÄMPFER, ${ }^{2}$ MARTIN ALTWEGG,${ }^{3}$ ILSE KERSTERS,${ }^{4}$ ANDREW LAMB,${ }^{5}$ \\ RENATA COOPMAN, ${ }^{1}$ JACQUELINE LÜTHY-HOTTENSTEIN, ${ }^{3}$ MARC VANCANNEYT, ${ }^{1}$ \\ PAUL JANSSEN, ${ }^{1}$ AND KAREL KERSTERS ${ }^{1}$ \\ Laboratorium voor Microbiologie ${ }^{1}$ and Laboratorium voor Microbiële Ecologie, ${ }^{4}$ Universiteit Gent, B-9000 Ghent, Belgium; \\ Institut für Angewandte Mikrobiologie, Justus-Liebig-Universität Giessen, D-35390 Giessen, Germany ${ }^{2}$; Institut für \\ Medizinische Mikrobiologie der Universität Zürich, CH-8028 Zürich, Switzerland ${ }^{3}$; and School of \\ Applied Sciences, Faculty of Science and Technology, Robert Gordon University, \\ Aberdeen AB1 1HG, Scotland, United Kingdom ${ }^{5}$
}

\begin{abstract}
We examined the taxonomic position of seven Aeromonas isolates, recovered from Flemish and Scottish drinking water production plants and reservoirs, which were previously recognized by numerical analysis of genomic AFLP fingerprints as members of an unknown Aeromonas taxon that most closely resembled the species Aeromonas bestiarum (DNA hybridization group [HG] 2). The new phenotypic and DNA-DNA hybridization data obtained in this study show that the $A$. bestiarum-like strains constitute a separate Aeramonas species, for which the name Aeromonas popoffii sp. nov. is being proposed. The new species exhibited an internal DNA relatedness ranging from 79 to $100 \%$ and was 22 to $63 \%$ related to the type or reference strains of other Aeromonas spp. The highest DNA binding values were determined with $A$. bestiarum (51 to $63 \%$ ), followed by Aeromonas hydrophila sensu stricto (HG1; 50 to 60\%) and Aeromonas salmonicida (HG3; 39 to 55\%). Although fingerprints generated by ribotyping and cellular fatty acid analysis often were highly similar, minor differences between the respective fingerprints were of significance for the differentiation of $A$. popoffii from its closest taxonomic neighbors, HG1, HG2, and HG3. Phenotypically, all seven strains of $A$. popoffi were positive for acid and gas production from D-glucose and glycerol, growth in KCN broth, arginine dihydrolase, DNase, VogesProskauer reaction, and resistance to vibriostatic agent $\mathrm{O} / 129$ and ampicillin but displayed negative reactions for production of urease, tryptophan deaminase, ornithine decarboxylase, and lysine decarboxylase (LDC). None of the strains displayed strong hemolytic activity. The lack of D-sucrose fermentation and LDC production and the ability to utilize DL-lactate as the sole energy and carbon source were useful characteristics for the biochemical separation of $A$. popoffii from $A$. bestiarum. Other Aeromonas spp. could be differentiated phenotypically from the new species by at least two features. The chromosomal $\mathrm{G}+\mathrm{C}$ content of $A$. popoffi ranges from 57.7 to 59.6 mol\%. Strain LMG 17541 is proposed as the type strain.
\end{abstract}

Members of the genus Aeromonas belong to the autochthonous microbiota of most freshwaters, raw drinking waters, and municipal sewage effluents (24). However, numerous reports on the incidence of aeromonads in cold-blooded animals (40), human clinical specimens $(14,35,47)$, food $(26,41)$, and soil (51) clearly demonstrate that the natural habitats of these organisms are not strictly limited to aquatic environments. In general, microbiologists have primarily focused on Aeromonas in relation to the furunculosis-causing fish pathogen Aeromonas salmonicida $(50,57)$ or because of the steadily growing notion that some mesophilic Aeromonas species are opportunistic human pathogens $(13,34)$. Nonetheless, and in spite of the increasing number of medical cases describing Aeromonasassociated extraintestinal infections and gastroenteritis, none of the known species has yet been recognized as a primary pathogen for humans (33).

Apart from the clinical relevance of Aeromonas, the taxonomy of this genus appears to be continuously changing due to the addition of newly described species $(2,17)$ and the reclassification or extended description of existing taxa $(27,28)$. In addition, the combined use of the terms phenospecies (i.e., taxon delineated on the basis of phenotypic characteristics)

* Corresponding author. Mailing address: Laboratorium voor Microbiologie, Universiteit Gent, K. L. Ledeganckstr. 35, B-9000 Ghent, Belgium. Phone: 329 2645249. Fax: 329 2645346. E-mail: geert.huys @rug.ac.be. and genomospecies (i.e., DNA hybridization group [HG]) in the current Aeromonas classification seems highly confusing to many taxonomists outside the field (8). At least 13 Aeromonas species have been validated so far $(2,3,7,9,17,22,23,46,53$, 56), of which some encompass several HGs (e.g., Aeromonas caviae HG4, HG5A, and HG5B, the latter also including Aeromonas media) or are further subdivided in genotypically identical biogroups (e.g., Aeromonas veronii biogroup sobria [HG8] and $A$. veronii biogroup veronii [HG10]).

In a recent study (29) of the genotypic diversity among 168 Aeromonas isolates, obtained from Flemish drinking water production plants, using the DNA fingerprinting technique AFLP a group of 24 strains remained unidentified against the AFLP-based identification library representing all currently described taxa in the genus Aeromonas. A numerical analysis of individual AFLP fingerprints revealed that the unidentified strains constituted a separate genotypic cluster that was most closely related to but clearly distinct from Aeromonas bestiarum, formerly referred to as $A$. hydrophila HG2 (2). In the course of a subsequent AFLP study (31), additional $A$. bestiarum-like strains were also discovered among a collection of mesophilic Aeromonas isolates originating from Scottish drinking water supplies.

The purpose of the present study was to examine the genomic and phenotypic relationships of the Flemish and Scottish $A$. bestiarum-like isolates to $A$. bestiarum and to other previously identified Aeromonas species. Based on the reported findings, it was concluded that this unknown group 
TABLE 1. $A$. popoffii strains used in this study ${ }^{a}$

\begin{tabular}{|c|c|c|c|}
\hline Strain $^{b}$ & Original designation & Source of isolation & Geographical origin \\
\hline LMG $17541^{\mathrm{T}}$ & IK-O-a-10-3 & Drinking water production plant (sampled after flocculation-decantation) & Oelegem (Belgium) \\
\hline LMG 17542 & IK-B-r-15-1 & Drinking water production plant (sampled from raw surface water) & De Blankaart (Belgium) \\
\hline LMG 17543 & IK-S-a-10-2 & Drinking water production plant (sampled after flocculation-decantation) & Snellegem (Belgium) \\
\hline LMG 17544 & IK-E-a-14-1 & Drinking water production plant (sampled after flocculation-decantation) & Eeklo (Belgium) \\
\hline LMG 17545 & IK-S-b-8-1 & Drinking water production plant (sampled after rapid sand filtration) & Snellegem (Belgium) \\
\hline LMG 17546 & AG-7 & Drinking water service reservoir & Udny Station (Scotland) \\
\hline LMG 17547 & AG-9 & Drinking water treatment plant (sampled after rapid sand filtration) & Turriff (Scotland) \\
\hline LMG $17548^{c}$ & IK-E-b-3-1 & Drinking water production plant (sampled after rapid sand filtration) & Eeklo (Belgium) \\
\hline
\end{tabular}

${ }^{a}$ In addition to the $7 \mathrm{~A}$. popoffii strains shown, $16 \mathrm{~A}$. bestiarum-like isolates (as delineated by numerical analysis of AFLP fingerprints [29]) were included for discriminatory phenotypic characterization (see Table 3 ).

${ }^{b}$ LMG, BCCM/LMG Culture Collection, Laboratorium voor Microbiologie, Universiteit Gent, Ghent, Belgium.

${ }^{c}$ Intermediate strain between $A$. bestiarum and $A$. popoffii (see Results and Discussion).

represents a new mesophilic member of the genus Aeromonas, for which the name Aeromonas popoffii is proposed. Furthermore, we also investigated the usefulness of ribotyping and fatty acid analysis as rapid and reliable techniques for the differentiation of $A$. popoffii from its closest taxonomic neighbors.

\section{MATERIALS AND METHODS}

Strains. For the description of the species $A$. popoffi, a total of seven representative strains were selected from the original collection of 24 Flemish (29) and 3 Scottish (31) isolates of the $A$. bestiarum-like group. Five of these seven strains were recovered in the period September 1992 to October 1993 from water samples taken during various treatment steps at four Flemish drinking water production plants (Table 1$)(30,39)$. The remaining two strains originated from two water supplies located in northeast Scotland that were routinely sampled from April 1995 to December 1996 to determine the incidence of mesophilic Aeromonas spp. in distributed potable waters (18). Strain LMG 17548 (Table 1), which was classified by numerical analysis of AFLP patterns as an isolate intermediate between HG2 and the HG2-like cluster (29), was also included for further taxonomic investigation. For a further verification of the discriminatory phenotypic characterizations (see Table 3 ), 16 additional members of the $A$. bestiarum-like AFLP cluster (29) were also included with the $7 A$. popoffi $i$ strains in Table 1 . In addition, type and reference strains of other Aeromonas species were used for DNA-DNA hybridization (see Table 2), antimicrobial susceptibility testing (data not shown), ribotyping (see Fig. 1), and fatty acid analysis (see Table 4). Unless otherwise stated, all strains were cultured aerobically on trypticase soy agar (TSA) containing $3 \%$ (wt/vol) Trypticase soy broth (BBL) and $1.5 \%$ (wt/vol) bacteriological agar no. 1 (Oxoid) at $28^{\circ} \mathrm{C}$ for $24 \mathrm{~h}$.

Physiological and biochemical characterization. All of the phenotypic characters listed below were tested for the first seven strains in Table 1 . In addition, the discriminatory tests shown in Table 3 were also performed for 16 other members of the $A$. bestiarum-like AFLP cluster (29) and strain LMG 17548.

Cell shape and Gram-staining characteristics were determined with cultures grown overnight on TSA medium (58). The oxidation-fermentation test was performed in $\mathrm{O} / \mathrm{F}$ basal medium supplemented with $1 \%$ (wt/vol) glucose as described by Hugh and Leifson (25). Production of a brown diffusible pigment was determined after 7 days on TSA medium. Hydrogen sulfide production; esculin hydrolysis, tryptophan deaminase, arginine dihydrolase, lysine and ornithine decarboxylase, urease, citrate and malonate alkalinization; hydrolysis of $o$-nitrophenyl- $\beta$-D-galactopyranoside, $p$-nitrophenyl ( $p \mathrm{NP})-\beta$-D-glucuronide, and $p N P-\beta$ - $D$-xyloside; and acid formation from $D$-glucose, $\mathrm{L}$-rhamnose, $\mathrm{D}$-sucrose, $\mathrm{D}$-xylose, adonitol, inositol, and D-sorbitol were tested with the Micronaut-E System (Merlin Diagnostica, Bornheim-Hersel, Germany), formerly the Titertek-Enterobac-Automated System (36). Kovacs cytochrome oxidase was tested by using commercially available test strips (Merck, Darmstadt, Germany). The following tests were performed as described previously (58): indole production (method 1), catalase activity (method 1), casein hydrolysis, gas production from D-glucose and glycerol, gelatinase activity (method 1), hemolysis of sheep blood (method 1), lecithinase activity, Tween 80 hydrolysis (method 2), motility, DNase activity (method 1), starch hydrolysis, susceptibility to vibriostatic agent $0 / 129$, nitrate and nitrite reduction, and the Voges-Proskauer reaction. Hydrolysis of chitin was performed according to the method of Lingappa and Lockwood (42). Growth in KCN medium was performed as described by Edwards and Fife (15), whereas salt tolerance was determined in nutrient broth containing $3,6,8$, or $10 \%$ (wt $/ \mathrm{vol}$ ) $\mathrm{NaCl}$. Growth at $37^{\circ} \mathrm{C}$ was determined in $3 \%$ (wt/vol) Trypticase soy broth. The following tests were performed as described previously (37): utilization of carbon sources (acetate, $N$-acetyl-D-glucosamine, cis-aconitate, trans-aconitate, adipate, adonitol, $\beta$-alanine, L-alanine, 4-aminobutyrate, $\mathrm{L}$-arabinose, arbutin, L-arginine, L-aspartate, azelate, D-cellobiose, citrate, citrullin, dulcitol, erythritol, ethanol, D-fructose, fumarate, D-galactose, D-gluconate, Dglucose, D-glucuronate, glutarate, L-glutamate, L-glutamine, glycerol, glycine, L-histidine, 3-hydroxybenzoate, 4-hydroxybenzoate, DL-3-hydroxybutyrate, inositol, itaconate, DL-lactate, lactose, L-leucine, L-malate, maltitol, D-maltose, Dmannose, D-mannitol, $\alpha$-D-melibiose, mesaconate, L-ornithine, oxoglutarate, phenylacetate, L-phenylalanine, L-proline, propionate, putrescine, pyruvate, $\mathrm{D}$ raffinose, L-rhamnose, D-ribose, salicin, L-serine, D-sorbitol, suberate, succinate, D-sucrose, D-trehalose, L-tryptophan, L-tyrosine, and D-xylose), fermentation of carbohydrates (acid production from L-arabinose, D-arabitol, D-cellobiose, dulcitol, erythritol, D-galactose, glycerol, lactose, D-maltose, D-mannitol, D-mannose, melibiose, methyl-D-glucoside, D-raffinose, salicin, and D-trehalose), and qualitative enzyme tests (using the chromogenic substrates L-alanine-p-nitroanilide [ $p \mathrm{NA}], 2$-deoxythymidine-5' $-p \mathrm{NP}$-phosphate, L-glutamate- $\gamma$-3-carboxy- $p \mathrm{NA}$, $p$ NP- $\alpha$-D-glucopyranoside, $p$ NP- $\beta$-D-glucopyranoside, $p$ NP-phenylphosphonate, bis- $p$ NP-phosphate, $p N P$-phosphoryl choline, and L-proline- $p$ NA). All biochemical tests were read after $48 \mathrm{~h}$ of incubation with the exception of the chitin hydrolysis test which was read after 7 days.

Antibiotic susceptibility testing. Susceptibilities to 72 different antibiotics were tested in 96-well microplates with Micronaut-S kits (Merlin Diagnostika). Nine microplates contained the 72 freeze-dried antibiotics in 12 different concentrations. From a $24( \pm 2)$-h-old culture that was grown on Sheep Blood Agar Base (Oxoid) at $30^{\circ} \mathrm{C}$, single colonies were picked and suspended in 3 to $5 \mathrm{ml}$ of a standardized sterile saline medium (Braun, Melsungen, Germany). This suspension was photometrically adjusted to a McFarland standard of 0.5 , which equals an $A_{560}$ value of about 0.12 , and $10 \mu \mathrm{l}$ of this suspension was then added to 10 $\mathrm{ml}$ of Iso-Sensitest broth (Oxoid). After thorough mixing, $100 \mu \mathrm{l}$ of this suspension was added to each well of the Micronaut-S microplates. The sealed plates were read after an incubation of $24 \pm 2 \mathrm{~h}$ at $30^{\circ} \mathrm{C}$ by using a microplate reader (Labsystems, Multiscan Multisoft). An $A_{540}$ value of $>0.1$ was considered a positive growth response.

Mol\% G + C determination and DNA-DNA hybridization. Chromosomal DNA of high molecular weight was isolated according to the method of Marmur (43). The moles percent guanine-plus-cytosine $(\mathrm{mol} \% \mathrm{G}+\mathrm{C})$ values were determined in $1 \times \mathrm{SSC}$ (sodium saline citrate; $0.15 \mathrm{M} \mathrm{NaCl}, 0.015 \mathrm{M}$ sodium citrate [ $\mathrm{pH} 7.0]$ ) from the midpoint of thermal denaturation as first described by Marmur and Doty (44) and reexamined by De Ley (11).

DNA-DNA hybridizations were performed by using the optical renaturation method of De Ley et al. (12). Prior to thermal denaturation in a boiling-water bath for $10 \mathrm{~min}$, the DNA solutions were brought to a concentration of $0.054 \mathrm{mM}$ in $0.1 \times$ SSC. The reassociation reactions were performed in $2 \times$ SSC by quickly cooling the DNA solutions to an optimal renaturation temperature $\left(T_{\mathrm{OR}}\right)$ of $76.9^{\circ} \mathrm{C}$. This temperature was calculated from the mean mol\% $\mathrm{G}+\mathrm{C}$ of the $A$. bestiarum-like strains (see Table 2) by using the equation $T_{\mathrm{OR}}=0.51 \times$ $(\mathrm{mol} \% \mathrm{G}+\mathrm{C})+47.0(19)$. The degree of binding was calculated from the renaturation rates determined from the decrease in $A_{260}$ over a period of $30 \mathrm{~min}$ according to De Ley et al. (12).

Ribosomal DNA gene restriction fragment analysis. For ribotyping purposes, strains were cultured overnight in Luria-Bertani broth, containing $1 \%$ (wt/vol) tryptone (Oxoid), $0.5 \%$ (wt/vol) yeast extract (Oxoid), and $1 \%$ (wt/vol) NaCl, at $28^{\circ} \mathrm{C}$ under continuous shaking. Total genomic DNA was extracted by using the standard miniprep procedure (6). Approximately $5 \mu \mathrm{g}$ of DNA was digested with the restriction endonuclease SmaI according to the manufacturer's instructions (Boehringer GmbH, Mannheim, Germany). Restriction fragments were separated in a $1.2 \%$ agarose gel submerged in TBE buffer $(89 \mathrm{mM}$ Tris, $89 \mathrm{mM}$ boric acid, $0.2 \mathrm{mM}$ EDTA [pH 8.0]), stained with ethidium bromide, and transferred to a nylon 66 membrane (BiodyneA; Pall Biosupport) according to the Southern blot procedure (59).

The construction of plasmid pGML1, which contains a 567-bp fragment of the $r m B$ gene of Escherichia coli, has been described previously by Martinetti Lucchini and Altwegg (45). Purification of pGML1 DNA from E. coli was performed by cesium chloride-ethidium bromide gradient centrifugation, and the purified 
plasmid DNA was labeled by nick translation with biotin-11-UTP (GIBCOBethesda Research Laboratories) (45). Nylon blots were hybridized with labelled plasmid pGML1 following standard protocols. The BluGene kit (GIBCO-Bethesda Research Laboratories) was used for visualizing the resulting hybrids according to the manufacturer's instructions. Reconstructed images of the visualized ribotyping band patterns in the low-molecular-weight zone $(0.8$ to $4.0 \mathrm{~kb})$ were scanned with a Scan Jet $4 c / T$ document scanner (Hewlett Packard). Further processing, calculation of the band-matching Dice coefficient, and cluster analysis by the unweighted pair-group method using arithmetic averages were carried out by using GelCompar software, version 3.1 (Applied Maths, Kortrijk, Belgium).

Gas-liquid chromatographic analysis of cellular FAMEs. Strains were inoculated on TSA medium containing Bacto agar (Difco) instead of bacteriological agar no. I (Oxoid) according to the quadrant streak technique and were incubated for $48 \mathrm{~h}$ at $28^{\circ} \mathrm{C}$. Cell harvesting, saponification of lipids, methylation of fatty acids, extraction of fatty acid methyl esters (FAMEs), and washing of extracts were done as described in the standardized protocol for the Microbial Identification System (MIDI; Microbial ID Inc.). Extracts were analyzed using a gas chromatograph (model HP5890A, Hewlett-Packard) equipped with a flame ionization detector, an automatic sampler, an integrator, and a personal computer (52). Identification and quantification of individual FAME profiles and calculation of mean profiles were performed by using the Microbial Identification System software package, version 3.9.

\section{RESULTS AND DISCUSSION}

DNA relatedness. The DNA hybridization data presented in Table 2 demonstrate the existence of a clear gap between the internal relatedness of the $A$. bestiarum-like group and their relatedness to the type and reference strains of all known Aeromonas taxa. Based on DNA-DNA hybridization experiments with strains LMG $17541^{\mathrm{T}}$ and LMG 17542 , the first seven strains in Table 1 exhibited an intragroup relatedness ranging from 79 to $100 \%$ (Table 2). The eighth strain in Table 1, i.e., the intermediate isolate LMG 17548 (29), is discussed further. DNA hybridization of strains LMG $17541^{\mathbf{T}}$ and LMG 17542 with the type and reference strains of the 13 species currently recognized in Aeromonas revealed that the two $A$. bestiarum-like isolates were 22 to $63 \%$ related to other Aeromonas spp. (Table 2). As would be expected from our previously reported AFLP data (29), high proportional degrees of DNA binding ranging from 51 to $63 \%$ were obtained with the type strain and two reference strains of the species $A$. bestiarum. Furthermore, Table 2 shows that strain LMG $2844^{\mathrm{T}}$ of $A$. hydrophila HG1 (DNA binding, 50 to $60 \%$ ) and strain LMG $3780^{\mathrm{T}}$ of $A$. salmonicida HG3 (DNA binding, 39 to $55 \%$ ) also displayed relatively high levels of genomic relatedness with strains LMG $17541^{\mathrm{T}}$ and LMG 17542. The finding of such high levels with representatives of HG1 (phenotypically $A$. hydrophila) and HG3 (phenotypically $A$. hydrophila or $A$. salmonicida) was not very surprising keeping in mind that several workers previously have experienced major difficulties in separating $\mathrm{HG} 2$ ( $A$. bestiarum) from $A$. hydrophila $\mathrm{HG} 1$ and $\mathrm{HG} 3$ solely on the basis of DNA-DNA hybridization experiments. For instance, Hänninen (20) reported levels of DNA relatedness between strains of HG2 and HG3 that were as high as $87 \%$ at an optimal reassociation temperature of $60^{\circ} \mathrm{C}$, whereas Ali and coworkers (2) showed that the type strain of $A$. bestiarum was 78 (divergence in melting temperature $\left[\Delta T_{m}\right], 6.0^{\circ} \mathrm{C}$ ) and $71 \%\left(\Delta T_{m}, 3.3^{\circ} \mathrm{C}\right)$ related at $60^{\circ} \mathrm{C}$ with the type strain of HG1 and the reference strain of HG3, respectively. As for the latter study, it should be mentioned that $\Delta T_{m}$ values within $A$. bestiarum did not exceed $2.0^{\circ} \mathrm{C}(2)$. Unfortunately, the optical renaturation method used in the current DNA hybridization study does not allow the determination of $\Delta T_{m}$ values. In conjunction with the previous findings of Hänninen (20) and Ali et al. (2), however, the new DNA relatedness data shown in Table 2 clearly indicate that the first seven strains in Table 1 are sufficiently different from $A$. bestiarum and from all other
TABLE 2. Mol\% $\mathrm{G}+\mathrm{C}$ of $A$. popoffii and DNA relatedness of $A$. popoffii strains LMG $17541^{\mathrm{T}}$ and LMG 17542 to other strains of $A$. popoffii and Aeromonas spp.

\begin{tabular}{|c|c|c|c|}
\hline \multirow{2}{*}{ Strain $^{a}$} & \multicolumn{2}{|c|}{$\begin{array}{c}\% \text { DNA } \\
\text { binding with }{ }^{b}:\end{array}$} & \multirow{2}{*}{$\begin{array}{l}\mathrm{mol} \% \\
\mathrm{G}+\mathrm{C}\end{array}$} \\
\hline & $\begin{array}{l}\text { LMG } \\
17541^{T}\end{array}$ & $\begin{array}{l}\text { LMG } \\
17542\end{array}$ & \\
\hline \multicolumn{4}{|l|}{ A. popoffi } \\
\hline LMG $17541^{\mathrm{T}}$ & 100 & & 57.7 \\
\hline LMG 17547 & 100 & 90 & \\
\hline LMG 17542 & 93 & 100 & 59.0 \\
\hline LMG 17546 & 87 & 89 & 58.6 \\
\hline LMG 17545 & 86 & 91 & 57.7 \\
\hline LMG 17544 & 83 & 80 & 59.6 \\
\hline LMG 17543 & 79 & 86 & 58.6 \\
\hline Aeromonas sp. LMG 17548 & 60 & 63 & \\
\hline A. hydrophila LMG $2844^{\mathrm{T}}\left(=\mathrm{ATCC} 7966^{\mathrm{T}}\right)$ & 50 & 60 & \\
\hline \multicolumn{4}{|l|}{ A. bestiarum } \\
\hline LMG $13444^{\mathrm{T}}\left(=\right.$ ATCC $\left.51108^{\mathrm{T}}\right)$ & 53 & 63 & \\
\hline LMG 13447 (=A 39) & 60 & 60 & \\
\hline LMG 13448 (=A 169) & 51 & 57 & \\
\hline A. salmonicida LMG $3780^{\mathrm{T}}\left(=\mathrm{ATCC} 33658^{\mathrm{T}}\right)^{\mathrm{c}}$ & 39 & 55 & \\
\hline A. caviae $\mathrm{LMG} 3775^{\mathrm{T}}\left(=\mathrm{ATCC} 15468^{\mathrm{T}}\right)$ & 39 & 54 & \\
\hline A. media LMG $9073^{\mathrm{T}}\left(=\mathrm{ATCC} 33907^{\mathrm{T}}\right)$ & 37 & 39 & \\
\hline A. eucrenophila LMG $3774^{\mathrm{T}}\left(=\operatorname{NCMB} 74^{\mathrm{T}}\right)$ & 42 & 41 & \\
\hline A. sobria LMG $3783^{\mathrm{T}}\left(=\mathrm{CIP} 7433^{\mathrm{T}}\right)$ & 40 & 46 & \\
\hline A. veronii $\mathrm{LMG} 9075^{\mathrm{T}}\left(=\mathrm{ATCC} 35604^{\mathrm{T}}\right)^{\mathrm{c}}$ & 45 & 43 & \\
\hline A. jandaei LMG $12221^{\mathrm{T}}\left(=\right.$ ATCC $\left.49568^{\mathrm{T}}\right)$ & 22 & 29 & \\
\hline A. encheleia LMG $16330^{\mathrm{T}}\left(=\right.$ CECT $\left.4342^{\mathrm{T}}\right)$ & 47 & 48 & \\
\hline A. schubertii LMG $9074^{\mathrm{T}}\left(=\right.$ ATCC $\left.43700^{\mathrm{T}}\right)$ & 39 & 43 & \\
\hline A. trota LMG $12223^{\mathrm{T}}\left(=\mathrm{ATCC} 49657^{\mathrm{T}}\right)$ & 44 & 43 & \\
\hline A. allosaccharophila LMG $14059^{\mathrm{T}}\left(=\mathrm{CECT} 4199^{\mathrm{T}}\right)$ & 36 & 40 & \\
\hline
\end{tabular}

${ }^{a}$ A, Institute of Medical Microbiology, Zürich, Switzerland; ATCC, American Type Culture Collection, Rockville, Md.; CECT, Colección Española de Cultivos Tipo, Universidad de Valéncia, Valencia, Spain; NCMB, National Collection of Marine Bacteria, Aberdeen, Scotland.

${ }^{b}$ Most of the reported values are the means from at least two determinations.

c In the current genotypic classification of the genus Aeromonas, the nonmotile psychrophilic species $A$. salmonicida resides in HG3 together with a group of motile, mesophilic $A$. hydrophila-like strains. However, both phenotypic groups behave identically in DNA hybridization (5). Similarly, the species $A$. veronii comprises two biogroups (i.e., sobria and veronii) that cannot be separated on the basis of DNA-DNA hybridization studies (5).

Aeromonas spp. to assign them to a new species, for which the name Aeromonas popoffii is proposed (see below).

Phenotypic differentiation of $A$. popoffii from other Aeromonas spp. The new mesophilic species can be distinguished from the psychrophilic fish pathogen $A$. salmonicida by its motility and its ability to grow in broth at $37^{\circ} \mathrm{C}(53)$. The differential test results of $A$. popoffii in relation to other mesophilic Aeromonas spp. reported in Table 3 were further confirmed for 16 other isolates of the $A$. bestiarum-like AFLP cluster (29) that can also be considered representative for the new species. Negative reactions in the tests for D-sucrose fermentation and lysine decarboxylation ( $\mathrm{LDC}^{-}$) are both essential biochemical features for the differentiation of $A$. popoffii from the most closely related species, $A$. hydrophila (HG1 and HG3) and $A$. bestiarum; in addition, these two characteristics also allowed differentiation from the taxa $A$. sobria and $A$. veronii biogroups sobria and veronii. A third distinguishing feature for $A$. bestiarum was found in the assimilation of DL-lactate (Table 3). The species $A$. caviae and $A$. media can be separated phenotypically from $A$. popoffii by their lack of gas production from glucose $\left(\mathrm{Gfg}^{-}\right)$and their ability to ferment D-sucrose, whereas utilization of DL-lactate and acid production from salicin are useful 
TABLE 3. Key tests for the phenotypic differentiation of $A$. popoffi from other mesophilic Aeromonas species $^{a}$

\begin{tabular}{|c|c|c|c|c|c|c|c|c|c|c|}
\hline \multirow{2}{*}{ Species } & \multirow{2}{*}{ Motility } & \multirow{2}{*}{$\begin{array}{l}\text { Production } \\
\text { of gas from } \\
\text { glucose }\end{array}$} & \multirow{2}{*}{$\begin{array}{l}\text { Utilization of } \\
\text { DL-lactate }\end{array}$} & \multicolumn{4}{|c|}{ Production of acid from: } & \multicolumn{2}{|c|}{ Decarboxylation of: } & \multirow{2}{*}{$\begin{array}{c}\text { Found in } \\
\text { clinical } \\
\text { specimens }\end{array}$} \\
\hline & & & & Salicin & D-Cellobiose & D-Mannitol & D-Sucrose & Ornithine & Lysine & \\
\hline A. popoffii ${ }^{b}$ & + & + & + & - & - & + & - & - & - & No \\
\hline A. hydrophila & + & $\mathrm{v}+$ & $+^{d}$ & $\mathrm{v}+$ & $\mathrm{v}-$ & + & + & - & + & Yes \\
\hline A. bestiarum ${ }^{e}$ & + & $v+$ & - & $\mathrm{v}+$ & $\mathrm{v}-$ & + & + & - & + & Yes \\
\hline A. caviae $^{f}$ & $\mathrm{v}+$ & - & $\mathrm{v}+$ & + & $\mathrm{v}+$ & + & + & - & - & Yes \\
\hline A. media $^{g}$ & - & - & + & $\mathrm{v}+$ & + & + & + & - & - & No \\
\hline A. eucrenophila ${ }^{h}$ & + & + & - & + & + & + & - & - & - & Yes \\
\hline A. sobria ${ }^{i}$ & + & $v+$ & $\mathrm{v}+$ & - & + & + & + & - & + & No \\
\hline $\begin{array}{l}\text { A. veronii biogroup } \\
\text { sobria } a^{j}\end{array}$ & + & $\mathrm{v}+$ & - & - & $\mathbf{v}+$ & + & + & - & + & Yes \\
\hline $\begin{array}{l}\text { A. veronii biogroup } \\
\text { veronii }\end{array}$ & $\mathrm{v}+$ & + & ND & + & $\mathrm{v}+$ & + & + & + & + & Yes \\
\hline A. jandaei ${ }^{l}$ & + & + & + & - & - & + & - & - & + & Yes \\
\hline A. encheleia ${ }^{h}$ & + & + & - & + & - & + & $v-$ & - & - & Yes \\
\hline A. schubertii ${ }^{m}$ & + & - & $\mathrm{v}+$ & - & - & - & - & - & $\mathrm{v}+$ & Yes \\
\hline A. trota $^{n}$ & + & $\mathrm{v}+$ & ND & - & + & + & $\mathrm{v}-$ & - & + & Yes \\
\hline A. allosaccharophila ${ }^{\circ}$ & + & + & ND & - & + & + & + & $v-$ & + & Yes \\
\hline
\end{tabular}

$a+, \geq 85 \%$ of the strains are positive;,$- \geq 85 \%$ of the strains are negative; $v+, 50$ to $84 \%$ of the strains are positive; $v-, 50$ to $84 \%$ of the strains are negative; ND, no data found.

${ }^{b}$ Data from this study are based on results obtained with 23 strains, including the first 7 strains in Table 1, of the A. bestiarum-like AFLP cluster (29).

c Data from references $1,2,4,5,10,16$, and 37 .

$d$ The substrate DL-lactate is used by $A$. hydrophila HG1 but not by $A$. hydrophila HG3 (5).

$e$ Data from references 2, 4, and 5 .

$f$ Data from references $1,4,5,10,16$, and 37 . The species $A$. caviae includes HG4, HG5A, and HG5B.

$g$ Data from references $3,4,5$, and 10 .

${ }^{h}$ Data from references 17,28 , and 55 .

$i$ Data from references $1,4,10$, and 37 .

Data from references 1,5 , and 10 .

${ }^{k}$ Data from references 10,23 , and 37 .

1 Data from references $1,4,7,10$, and 37 .

${ }^{m}$ Data from references $1,4,22$, and 37 .

${ }^{n}$ Data from references 4,9 , and 37 .

D Data from reference 46.

characteristics to discriminate between the new species and the nonpathogenic species $A$. eucrenophila and $A$. encheleia. The clinically relevant species $A$. jandaei and $A$. schubertii are both $\mathrm{LDC}^{+}$and can also be differentiated from $A$. popoffi $i$ by their hemolytic activity (7). In addition, members of $A$. schubertii are $\mathrm{Gfg}^{-}$and fail to ferment D-mannitol. A positive result in the LDC test and the ability to produce acid from D-cellobiose allow the separation of $A$. popoffi from $A$. allosaccharophila and $A$. trota. The latter species can also be separated from $A$. popoffii by its susceptibility to ampicillin (9).

The antibiotic resistance patterns of $A$. popoffii and $A$. bestiarum were generally very similar (data not shown). In the species description of $A$. popoffi $i$, results of susceptibility testing are reported for a selection of 20 frequently used antibiotics.

Ribotyping and fatty acid profiling of $\boldsymbol{A}$. popoffii. Despite the availability of several discriminatory biochemical tests, strains of HG1, HG2, and HG3 (phenotype $A$. hydrophila) were often very difficult to separate in routine identification because of their close phenotypic relationship $(1,5,20)$. In this context, the definition of $A$. popoffii as a new Aeromonas taxon that is closely related to these three HGs (Table 2) might give rise to additional problems concerning the correct identification of Aeromonas populations at the species level in ecotaxonomic surveys. In addition to the high discriminative power displayed by AFLP analysis (29), we also decided to evaluate two more frequently used fingerprinting methods as rapid and reliable tools for differentiating $A$. popoffii from its closest taxonomic neighbors.

A visual comparison of reconstructed ribotyping patterns clearly shows that the seven $A$. popoffi $i$ strains can be readily distinguished from the type strains of $A$. hydrophila (HG1) and $A$. bestiarum (HG2) and the reference strain of $A$. hydrophila HG3 by their typical lack of bands in the molecular weight region between 0.8 and $1.6 \mathrm{~kb}$ (Fig. 1). Numerical analysis of the reconstructed images using a band-based similarity coefficient (Fig. 1) confirmed the status of $A$. popoffii as a separate taxon in relation to members of the former $A$. hydrophila complex and further indicated that $A$. bestiarum and $A$. hydrophila

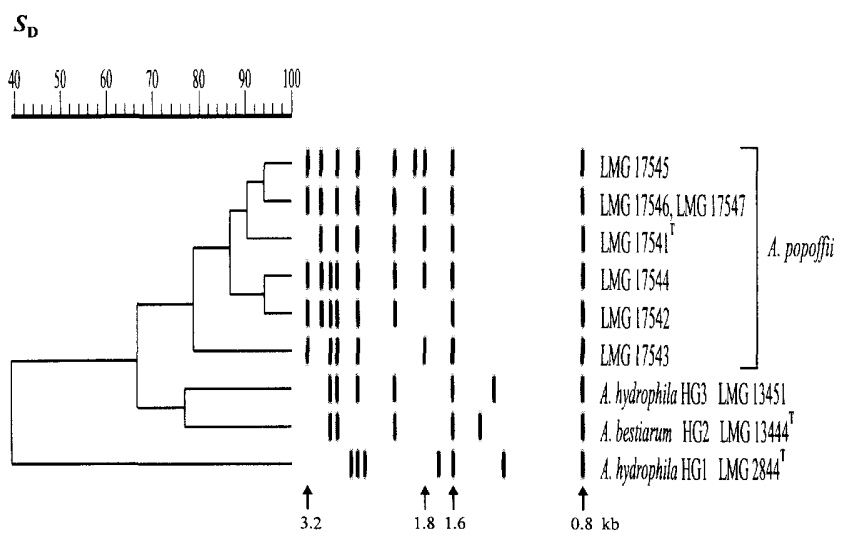

FIG. 1. Clustering analysis (unweighted pair-group method using arithmetic averages) of reconstructed ribotyping patterns generated from seven $A$. popoffi strains, type and reference strains of $A$. hydrophila (HG1 and HG3, respectively), and the type strain of $A$. bestiarum (HG2). Similarities are expressed as the band-matching Dice coefficient $\left(S_{\mathrm{D}}\right)$. Positions of the low-molecular-weight markers are indicated by arrows. 
TABLE 4. Major fatty acids of $A$. popoffi, A. hydrophila (HG1 and HG3), and A. bestiarum (HG2)

\begin{tabular}{|c|c|c|c|c|}
\hline \multirow{2}{*}{ Fatty acid ${ }^{a}$} & \multicolumn{4}{|c|}{ Mean $\%$ composition $(\mathrm{SD})^{b}$} \\
\hline & $\begin{array}{l}\text { A. popoffii } \\
(n=7)\end{array}$ & $\begin{array}{l}\text { A. hydrophila (HG1) } \\
(n=5)\end{array}$ & $\begin{array}{c}\text { A. bestiarum (HG2) } \\
(n=4)\end{array}$ & $\begin{array}{c}\text { A. hydrophila (HG3) } \\
(n=5)\end{array}$ \\
\hline \multicolumn{5}{|l|}{ Straight } \\
\hline 12:0 & $6.41(0.36)$ & $6.65(0.90)$ & $7.10(0.53)$ & $7.29(0.35)$ \\
\hline 14:0 & $2.49(0.47)$ & $4.38(0.72)$ & $3.19(0.39)$ & $1.68(0.66)$ \\
\hline $15: 0$ & $1.02(0.21)$ & $1.80(0.58)$ & $1.48(0.26)$ & $1.03(0.46)$ \\
\hline $16: 0$ & $17.2(0.91)$ & $17.9(1.64)$ & $15.5(1.11)$ & $19.4(2.45)$ \\
\hline $17: 1 \omega 8 c^{c}$ & $1.01(0.28)$ & $1.56(0.63)$ & $1.73(0.40)$ & $1.51(0.63)$ \\
\hline $17: 0$ & $0.77(0.30)$ & $1.35(0.63)$ & $1.15(0.29)$ & $1.30(0.55)$ \\
\hline \multicolumn{5}{|l|}{ Branched } \\
\hline $13: 0$ iso & $1.41(0.15)$ & $0.92(0.24)$ & $0.81(0.16)$ & $0.75(0.23)$ \\
\hline $15: 0$ iso & $0.94(0.32)$ & $1.44(0.58)$ & $1.02(0.35)$ & tr \\
\hline $16: 0$ iso & $\operatorname{tr}$ & $1.19(0.77)$ & $1.05(0.71)$ & $0.93(0.39)$ \\
\hline iso $17: 1 \omega 9 c^{c}$ & $2.14(1.00)$ & $1.22(0.44)$ & $1.27(0.29)$ & $1.61(0.57)$ \\
\hline $17: 0$ iso & $3.06(0.50)$ & $1.39(0.64)$ & $1.73(0.41)$ & $3.68(1.24)$ \\
\hline 17:0 10 methyl & $0.85(0.36)$ & $1.42(1.06)$ & $1.49(0.38)$ & $\operatorname{tr}$ \\
\hline Branched hydroxy, $15: 0$ iso $3 \mathrm{OH}$ & $3.47(0.39)$ & $1.56(0.42)$ & $2.43(0.33)$ & $2.42(0.79)$ \\
\hline Unknown $14.503^{d}$ & $0.60(0.08)$ & ND & ND & $0.73(0.12)$ \\
\hline \multicolumn{5}{|l|}{ Summed feature $e^{e}$} \\
\hline 3 & $7.92(0.54)$ & $8.42(1.67)$ & $8.78(1.54)$ & $7.54(0.35)$ \\
\hline 4 & $35.3(2.34)$ & $30.6(1.74)$ & $33.5(1.59)$ & $35.9(3.53)$ \\
\hline 7 & $8.71(1.37)$ & $12.0(1.46)$ & $9.76(0.78)$ & $10.4(2.46)$ \\
\hline 9 & $1.02(0.39)$ & ND & ND & ND \\
\hline
\end{tabular}

${ }^{a}$ The fatty acids 12:0 iso, unknown $11.798,13: 0,12: 03 \mathrm{OH}, 14: 1$ iso $\mathrm{E}, 14: 0$ iso, unknown $13.691,14: 0$ iso $3 \mathrm{OH}, 15: 03 \mathrm{OH}, 17: 0$ anteiso, 17:1 $\omega 6 c$, 18:0, and summed feature 2 had mean values of less than $0.6 \%$ and are therefore not listed.

${ }^{b}$ Means (and standard deviations) were calculated regardless of the fact that a particular fatty acid was not produced by all strains within a taxon. $n$, number of strains

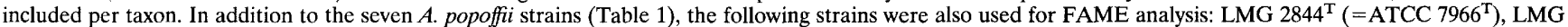
13443, LMG 13440, LMG 13658, and LMG 13660 of $A$. hydrophila (HG1); LMG 13444 ${ }^{\mathrm{T}}$ (=ATCC 51108 ${ }^{\mathrm{T}}$ ), LMG 13447, LMG 13448, and LMG 13446 of $A$. bestiarum (HG2); and LMG 13449, LMG 13450, LMG 13451, LMG 13453, and LMG 13675 of $A$. hydrophila (HG3). Detailed descriptions of these strains have been reported elsewhere $(2,32)$. ND, not detected; tr, trace amount $(<0.6 \%)$.

${ }^{c}$ For unsaturated fatty acids, the position of the double bond can be located by counting from the $\omega$ or methyl end of the carbon chain. cis isomers are indicated by the suffix $c$.

${ }^{d}$ Unknown fatty acids have no name listed in the Peak Library File of the MIDI system and can therefore only be indicated by their equivalent chain length.

${ }^{e}$ Summed features represent groups of two or three fatty acids which cannot be separated by gas-liquid chromatography with the MIDI system. Summed feature 3 contains 16:1 iso I and/or 14:0 $3 \mathrm{OH}$, summed feature 4 comprises 15:0 iso $2 \mathrm{OH}, 16: 1 \omega 7 t$, and/or 16:1 $\omega 7 \mathrm{c}$, and summed feature 7 contains one or more of the following isomers: 18:1 $\omega 7 c, 18: 1 \omega 9 t$, and/or 18:1 $\omega 12 t$ (the suffix $t$ indicates a trans isomer). Summed feature 9 represents unknown 18.846, unknown 18.858, and/or the cyclopropane fatty acid 19:0 cyclo $\omega 10 \mathrm{c}$. In this context, it should be mentioned that cyclic fatty acids only rarely occur in Aeromonas $(21,32,38)$.

HG3 were its closest taxonomic neighbors. Interestingly, Martinetti Lucchini and Altwegg (45) found that all 20 strains of HG2 and HG3 included in their ribotyping study displayed a major band in the zone from 0.8 to $1.6 \mathrm{~kb}$. To a lesser extent, the presence or absence of the bands with an approximate molecular weight of 1.8 and $3.2 \mathrm{~kb}$ may also be considered as possible discriminating features for the new species.

Following gas-liquid chromatographic analysis of their FAMEs, the mean cellular fatty acid composition of $A$. popoffi was compared with the mean profiles obtained with representative strains of the taxa HG1, HG2, and HG3. As shown in Table 4, only one minor compound was found to be of qualitative significance for the chemotaxonomic characterization of A. popoffi. Summed feature 9, a component that contains the cyclic fatty acid 19:0 cyclo $\omega 10 \mathrm{c}$ and/or one or both unknown fatty acids with equivalent chain lengths, 18.846 and 18.858 (Table 4), was produced by all seven strains of $A$. popoffii (range, 0.50 to $1.55 \%$ ) but remained undetected in strains of the other three HGs examined. The fatty acids that were present in all four Aeromonas taxa generally showed very little quantitative variation. Repeated FAME analyses of three strains of each $\mathrm{HG}$ tested clearly confirmed that summed feature 9 should be regarded as the most significant diagnostic compound for the separation of $A$. popoffii from HG1, HG2, and HG3 by cellular fatty acid analysis.
Intermediate strain LMG 17548. In the course of a previous AFLP study (29), it was suggested that the drinking water isolate $\mathrm{LMG} 17548$ might represent a genotypic intermediate between $A$. bestiarum and the HG2-like group now proposed as $A$. popoffii. This is now substantiated by new DNA hybridization data showing that strain LMG 17548 is 60 to $63 \%$ (Table 2) and 66 to $67 \%$ (data not shown) related to representatives of $A$. popoffii and $A$. bestiarum, respectively. Phenotypically, strain LMG 17548 could be easily excluded from $A$. popoffi (Table 3 ) by its ability to produce acid from D-sucrose and by its negative reaction in the DL-lactate assimilation test, whereas a positive result in the fermentation of D-sorbitol and the lack of gas production from glucose allowed the differentiation of this strain from $A$. bestiarum (2) (individual data not shown). In addition, the intermediate strain also exhibited an atypical ribotyping pattern (comprising a band of $1.4 \mathrm{~kb}$ ) and fatty acid profile (no production of summed feature 9) (results not shown). The possibility that strain LMG 17548 might belong to one of the other existing Aeromonas species was ruled out by comparison of its AFLP fingerprint with the genotypic Aeromonas database AERO94 (29). In view of these findings, it can be expected that the accumulation of more atypical $A$. bestiarum and $A$. popoffii strains might stimulate further systematic research on the relative position of this isolate in the genus Aeromonas. 
Description of Aeromonas popoffii sp. nov. We propose the name Aeromonas popoffii (po.pof' fi.i. M. L. gen. n. popoffii, of Popoff) for the first seven strains in Table 1. The species is named after Michel Y. Popoff, a French microbiologist who has greatly contributed to our current knowledge of the phenotypic and genotypic relationships among the mesophilic members of the genus Aeromonas (53-55).

All seven strains of $A$. popoffii (Table 1 ) display the following characteristics typical for the genus Aeromonas: gram-negative straight motile rods, chemoorganotrophic with both oxidative and fermentative metabolism, cytochrome oxidase and catalase positive, reduction of nitrate to nitrite without the production of gas, and resistance to vibriostatic agent $\mathrm{O} / 129$. Optimal growth occurs after $24 \mathrm{~h}$ at $28^{\circ} \mathrm{C}$ on TSA medium, but all strains also grow at $37^{\circ} \mathrm{C}$ in broth. No brown water-soluble pigment is produced on TSA medium. Acid and gas are produced from D-glucose and glycerol. Growth occurs in $\mathrm{KCN}$ broth but not in the presence of 3, 6, 8, and $10 \%$ (wt/vol) $\mathrm{NaCl}$. Arginine dihydrolase, DNase, indole (except strains LMG $17541^{\mathrm{T}}$ and LMG 17546), and Voges-Proskauer positive. No production of urease, tryptophan deaminase, ornithine and lysine decarboxylase. Production of $\mathrm{H}_{2} \mathrm{~S}$ by four of the seven strains. Alkalinization of citrate (except strains LMG 17544 and LMG 17546) and malonate (except strain LMG 17544).

The following substrates are used by all seven $A$. popoffii strains as the sole carbon and energy source: $N$-acetyl-D-glucosamine, L-alanine (except strain LMG 17547), L-aspartate, citrate (except strains LMG 17543 and LMG 17544), D-fructose (except strains LMG $17541^{\mathrm{T}}$ and LMG 17545), fumarate, D-galactose, D-gluconate, D-glucose, L-glutamate, L-glutamine, glycerol, L-histidine, DL-lactate (except strain LMG 17546), L-malate, D-mannitol, D-mannose, D-maltose, putrescine, pyruvate, $\mathrm{D}$-ribose, succinate, $\mathrm{L}$-serine, $\mathrm{D}$-trehalose, and L-tyrosine. None of the strains use acetate, $c i s$-aconitate, trans-aconitate, adipate, adonitol, $\beta$-alanine, 4-aminobutyrate, arbutin, L-arginine (except strains LMG 17544 and LMG 17546), azelate, D-cellobiose, citrullin, dulcitol, ethanol, erythritol, D-glucuronate, glutarate, glycine, 3-hydroxybenzoate, 4-hydroxybenzoate, DL-3-hydroxybutyrate, inositol, itaconate, lactose (except strain LMG 17542), L-leucine, maltitol, $\alpha$-D-melibiose, mesaconate, L-ornithine, oxoglutarate, phenylacetate, L-phenylalanine, L-proline, propionate, D-raffinose, L-rhamnose, salicin, D-sorbitol, suberate, D-sucrose, L-tryptophan, and D-xylose.

Acid is uniformly produced from D-galactose, D-maltose (except strain LMG 17546), D-mannitol, D-mannose, methyl-Dglucoside, and D-trehalose but not from adonitol, D-arabitol, D-cellobiose, dulcitol, erythritol, inositol, lactose, $\alpha$-D-melibiose, D-raffinose, L-rhamnose, salicin, D-sorbitol, D-sucrose, and D-xylose.

All $A$. popoffii strains hydrolyze the following substrates: Lalanine- $p \mathrm{NA}$, casein, 2-deoxythymidine-5'- $p$ NP-phosphate, gelatin, lecithin, bis- $p N P$-phosphate, ortho-nitrophenyl- $\beta$-Dgalactopyranoside, $p \mathrm{NP}$-phenylphosphonate, $p \mathrm{NP}$-phosphoryl choline, L-proline-pNA, starch, and Tween 80 . None of the strains are able to hydrolyze chitin, esculin, L-glutamate$\gamma$-3-carboxy- $p$ NA, $p$ NP- $\alpha$-D-glucopyranoside, $p N P-\beta$-D-glucuronide, and $p \mathrm{NP}-\beta$-D-xyloside.

All $A$. popoffii strains listed in Table 1 are resistant to amoxicillin, ampicillin, clarithromycin, oxacillin, penicillin $\mathrm{G}$, teicoplanin, and vancomycin but are sensitive to amikacin, cefotaxim, ceftazidim, chloramphenicol, gentamicin, kanamycin, mezlocillin, netilmicin, piperacillin, spectinomycin, tetracycline, tobramycin, and trimethoprim according to the interpretive standards provided by the National Committee for Clinical Laboratory Standards $(48,49)$.

The $\mathrm{G}+\mathrm{C}$ content ranges from 57.7 to $59.6 \mathrm{~mol} \%$ (Table 2).
Isolated from drinking water production plants and reservoirs (Table 1). One isolate (strain LMG 17544) displayed weak hemolytic activity after 7 days of incubation.

The type strain is strain LMG 17541; it has been deposited in the BCCM/LMG Culture Collection of the Laboratorium voor Microbiologie, Universiteit Gent, Ghent, Belgium. The $\mathrm{G}+\mathrm{C}$ content of this strain is $57.7 \mathrm{~mol} \%$.

\section{ACKNOWLEDGMENTS}

This research was carried out in the framework of contracts G.O.A. 91/96-2 of the Ministerie van de Vlaamse Gemeenschap, Bestuur Wetenschappelijk Onderzoek (Belgium) and BIO2-CT94-3098 of the European Commission. K.K. is indebted to the Fund for Scientific Research, Flanders, Belgium, for research and personnel grants and to the Prime Minister's Services, Federal Office for Scientific, Technical and Cultural Affairs, Brussels, Belgium, for financial support.

P.K. thanks Merlin Diagnostika GmbH (Bornheim-Hersel, Germany) for supplying the kits for antibiotic resistance testing.

\section{REFERENCES}

1. Abott, S. L., W. K. W. Cheung, S. Kroske-Bystrom, T. Malekzadeh, and M. J. Janda. 1992. Identification of Aeromonas strains to the genospecies level in the clinical laboratory. J. Clin. Microbiol. 30:1262-1266.

2. Ali, A., A. M. Carnahan, M. Altwegg, J. Lüthy-Hottenstein, and S. W. Joseph. 1996. Aeromonas bestianum sp. nov. (formerly genomospecies DNA group $2 A$. hydrophila), a new species isolated from non-human sources. Med. Microbiol. Lett. 5:156-165.

3. Allen, D., B. Austin, and R. R. Colwell. 1983. Aeromonas media, a new species isolated from river water. Int. J. Syst. Bacteriol. 33:599-604.

4. Altwegg, M., and J. Lüthy-Hottenstein. 1991. Methods for the identification of DNA hybridization groups in the genus Aeromonas. Experientia 47:403406.

5. Altwegg, M., A. G. Steigerwalt, R. Altwegg-Bissig, J. Lüthy-Hottenstein, and D. J. Brenner. 1990. Biochemical identification of Aeromonas genospecies isolated from humans. J. Clin. Microbiol. 28:258-264.

6. Ausubel, F. M., R. Brent, R. E. Kingston, D. D. Moore, J. G. Seidman, J. A. Smith, and K. Struhl. 1989. Current protocols in molecular biology. John Wiley \& Sons, Chichester, United Kingdom.

7. Carnahan, A., G. R. Fanning, and S. W. Joseph. 1991. Aeromonas jandaei (formerly genospecies DNA group 9 A. sobria), a new sucrose-negative species isolated from clinical specimens. J. Clin. Microbiol. 29:560-564

8. Carnahan, A. M., and M. Altwegg. 1996. Taxonomy, p. 1-38. In B. Austin, M Altwegg, P. J. Gosling, and S. Joseph (ed.), The genus Aeromonas. John Wiley \& Sons, Chichester, United Kingdom

9. Carnahan, A. M., T. Chakraborty, G. R. Fanning, D. Verma, A. Ali, J. M. Janda, and S. W. Joseph. 1991. Aeromonas trota sp. nov., an ampicillinsusceptible species isolated from clinical specimens. J. Clin. Microbiol. 29. 1206-1210.

10. Carnahan, A. M., and S. W. Joseph. 1993. Systematic assessment of geographically and clinically diverse aeromonads. Syst. Appl. Microbiol. 16:7284.

11. De Ley, J. 1970. Reexamination of the association between melting point, buoyant density, and chemical base composition of deoxyribonucleic acid. J. Bacteriol. 101:738-754.

12. De Ley, J., H. Cattoir, and A. Reynaerts. 1970 . The quantitative measurement of DNA hybridization from renaturation rates. Eur. J. Biochem. 12 $133-142$.

13. Deodhar, L. P., K. Saraswathi, and A. Varudkar. 1991. Aeromonas spp. and their association with human diarrheal disease. J. Clin. Microbiol. 29:853856.

14. Dryden, M., and R. Munro. 1989. Aeromonas septicemia: relationship of species and clinical features. Pathology 21:111-114.

15. Edwards, P. R., and M. A. Fife. 1956. Cyanide media in the differentiation of enteric bacteria. Appl. Microbiol. 4:46.

16. Esteve, C. 1995. Numerical taxonomy of Aeromonadaceae and Vibrionaceae associated with reared fish and surrounding fresh and brackish water. Syst. Appl. Microbiol. 18:391-402.

17. Esteve, C., M. C. Gutiérrez, and A. Ventosa. 1995. Aeromonas encheleia sp nov., isolated from European eels. Int. J. Syst. Bacteriol. 45:462-466.

18. Gavriel, A. A., J. P. B. Landre, and A. J. Lamb. Incidence of mesophilic Aeromonas within a public drinking water supply in north-east Scotland. J. Appl. Microbiol., in press.

19. Gillis, M., J. De Ley, and M. De Cleene. 1970. The determination of molecular weight of bacterial genome DNA from renaturation rates. Eur. J. Biochem. 12:143-153.

20. Hänninen, M.-L. 1994. Phenotypic characteristics of the three hybridization groups of Aeromonas hydrophila complex isolated from different sources. J. Appl. Bacteriol. 76:455-462. 
21. Hansen, W., J. Freney, M. Labbe, F. Renaud, E. Yourassowsky, and J. Fleurette. 1991. Gas-liquid chromatographic analysis of cellular fatty acid methyl esters in Aeromonas species. Zentralbl. Bakteriol. 275:1-10.

22. Hickman-Brenner, F. W., G. R. Fanning, M. J. Arduino, D. J. Brenner, and J. J. Farmer III. 1988. Aeromonas schubertii, a new mannitol-negative species found in human clinical specimens. J. Clin. Microbiol. 26:1561-1564.

23. Hickman-Brenner, F. W., K. L. MacDonald, A. G. Steigerwalt, G. R. Fanning, D. J. Brenner, and J. J. Farmer III. 1987. Aeromonas veronii, a new ornithine decarboxylase-positive species that may cause diarrhea. J. Clin. Microbiol. 25:900-906.

24. Holmes, P., L. M. Niccolls, and D. P. Sartory. 1996. The ecology of mesophilic Aeromonas in the aquatic environment, p. 127-150. In B. Austin, M. Altwegg, P. J. Gosling, and S. Joseph (ed.), The genus Aeromonas. John Wiley \& Sons, Chichester, United Kingdom.

25. Hugh, R., and E. Leifson. 1953. The taxonomic significance of fermentative versus oxidative metabolism of carbohydrates by various Gram negative bacteria. J. Bacteriol. 66:24-27.

26. Hunter, P. R., B. Cooper-Poole, and H. Hornby. 1992. Isolation of Aeromonas hydrophila from cooked tripe. Lett. Appl. Microbiol. 15:222-223.

27. Huys, G., M. Altwegg, M.-L. Hänninen, M. Vancanneyt, L. Vauterin, R. Coopman, U. Torck, J. Lüthy-Hottenstein, P. Janssen, and K. Kersters. 1996. Genotypic and chemotaxonomic description of two subgroups in the species Aeromonas eucrenophila and their affiliation to $A$. encheleia and Aeromonas DNA hybridization group 11. Syst. Appl. Microbiol. 19:616-623.

28. Huys, G., P. Kämpfer, M. Altwegg, R. Coopman, P. Janssen, M. Gillis, and K. Kersters. 1997. Inclusion of Aeromonas DNA hybridization group 11 in Aeromonas encheleia and extended descriptions of the species Aeromonas eucrenophila and $A$. encheleia. Int. J. Syst. Bacteriol. 47:1157-1164.

29. Huys, G., I. Kersters, R. Coopman, P. Janssen, and K. Kersters. 1996. Genotypic diversity among Aeromonas isolates recovered from drinking water production plants as revealed by AFLPTM analysis. Syst. Appl. Microbiol. 19:428-435.

30. Huys, G., I. Kersters, M. Vancanneyt, R. Coopman, P. Janssen, and K. Kersters. 1995. Diversity of Aeromonas sp. in Flemish drinking water production plants as determined by gas-liquid chromatographic analysis of cellular fatty acid methyl esters (FAMEs). J. Appl. Bacteriol. 78:445-455.

31. Huys, G., and A. Lamb. Unpublished data.

32. Huys, G., M. Vancanneyt, R. Coopman, P. Janssen, E. Falsen, M. Altwegg, and K. Kersters. 1994. Cellular fatty acid composition as a chemotaxonomic marker for the differentiation of phenospecies and hybridization groups in the genus Aeromonas. Int. J. Syst. Bacteriol. 44:651-658.

33. Janda, J. M. 1991. Recent advances in the study of the taxonomy, pathogenicity, and infectious syndromes associated with the genus Aeromonas. Clin. Microbiol. Rev. 4:397-410.

34. Janda, J. M., L. S. Guthertz, R. P. Kokka, and T. Shimada. 1994. Aeromonas species in septicemia: laboratory characteristics and clinical observations. Clin. Infect. Dis. 19:77-83.

35. Joseph, S. W., A. M. Carnahan, P. R. Brayton, G. R. Fanning, R. Almazan, C. Drabick, E. W. Trudo, Jr., and R. R. Colwell. 1991. Aeromonas jandaei and Aeromonas veronii dual infection of a human wound following aquatic exposure. J. Clin. Microbiol. 29:565-569.

36. Kämpfer, P. 1990. Evaluation of the Titertek-Enterobac-Automated system (TTE-AS) for identification of members of the family Enterobacteriaceae. Zentralbl. Bakteriol. 273:341-351.

37. Kämpfer, P., and M. Altwegg. 1992. Numerical classification and identification of Aeromonas genospecies. J. Appl. Bacteriol. 72:341-351.

38. Kämpfer, P., K. Blasczyk, and G. Auling. 1994. Characterization of Aeromonas genomic species by using quinone, polyamine, and fatty acid patterns. Can. J. Microbiol. 40:844-850.

39. Kersters, I., L. Van Vooren, G. Huys, P. Janssen, K. Kersters, and W. Verstraete. 1995. Influence of temperature and process technology on the occurrence of Aeromonas species and hygienic indicator organisms in drink- ing water production plants. Microb. Ecol. 30:203-218.

40. Khardori, N., and V. Fainstein. 1988. Aeromonas and Plesiomonas as etiological agents. Annu. Rev. Microbiol. 42:395-419.

41. Krovacek, K., A. Faris, S. B. Baloda, M. Peterz, T. Lindberg, and I. Mansson. 1992. Prevalence and characterization of Aeromonas spp. isolated from foods in Uppsala, Sweden. Food Microbiol. 9:29-36.

42. Lingappa, Y., and J. L. Lockwood. 1961. A chitin medium for isolation, growth and maintenance of actinomycetales. Náture 189:158-159.

43. Marmur, J. 1961. A procedure for the isolation of deoxyribonucleic acid from micro-organisms. J. Mol. Biol. 3:208-218.

44. Marmur, J., and P. Doty. 1962. Determination of the base composition of deoxyribonucleic acid from its thermal denaturation temperature. J. Mol. Biol. 5:109-118.

45. Martinetti Lucchini, G., and M. Altwegg. 1992. rRNA gene restriction patterns as taxonomic tools for the genus Aeromonas. Int. J. Syst. Bacteriol. 42:384-389.

46. Martinez-Murcia, A. J., C. Esteve, E. Garay, and M. D. Collins. 1992. Aeromonas allosaccharophila sp. nov., a new mesophilic member of the genus Aeromonas. FEMS Microbiol. Lett. 91:199-206.

47. Namdari, H., and E. J. Bottone. 1990. Microbiologic and clinical evidence supporting the role of Aeromonas caviae as a pediatric enteric pathogen. J. Clin. Microbiol. 28:837-840.

48. National Committee for Clinical Laboratory Standards. 1993. Approved standard M7-A3. Methods for dilution antimicrobial susceptibility tests for bacteria that grow aerobically. National Committee for Clinical Laboratory Standards, Villanova, $\mathrm{Pa}$.

49. National Committee for Clinical Laboratory Standards. 1993. Tentative standard M6-T. Evaluating production lots of dehydrated Mueller-Hinton agar. National Committee for Clinical Laboratory Standards, Villanova, Pa.

50. O'Brien, F., J. Mooney, D. Ryan, E. Powell, M. Tiney, P. R. Smith, and R. Powell. 1994. Detection of Aeromonas salmonicida, causal agent of furunculosis in salmonid fish, from the tank effluent of hatchery-reared Atlantic salmon smolts. Appl. Environ. Microbiol. 60:3874-3877.

51. Osborn, A. M., K. D. Bruce, P. Strike, and D. A. Ritchie. 1993. Polymerase chain reaction-restriction fragment length polymorphism analysis shows divergence among mer determinants from gram-negative soil bacteria indistinguishable by DNA-DNA hybridization. Appl. Environ. Microbiol. 59: 4024-4030.

52. Osterhout, G. J., V. H. Shull, and J. D. Dick. 1991. Identification of clinical isolates of gram-negative nonfermentative bacteria by an automated cellular fatty acid identification system. J. Clin. Microbiol. 29:1822-1830.

53. Popoff, M. 1984. Genus Aeromonas Kluyver and van Niel 1936, 398 $8^{A L}$, p. 545-548. In N. R. Krieg and J. G. Holt (ed.), Bergey's manual of systematic bacteriology, vol. 1. The Williams \& Wilkins Co., Baltimore, Md.

54. Popoff, M., and M. Véron. 1976. A taxonomic study of the Aeromanas hydrophila-Aeromonas punctata group. J. Gen. Microbiol. 94:11-22.

55. Popoff, M. Y., C. Coynault, M. Kiredjian, and M. Lemelin. 1981. Polynucleotide sequence relatedness among motile Aeromonas species. Curr. Microbiol. 5:109-114.

56. Schubert, R. H. W., and M. Hegazi. 1988. Aeromonas eucrenophila species nova Aeromonas caviae a later and illegitimate synonym of Aeromonas punctata. Zentralbl. Bakteriol. Parasitenkd. Infektionskr. Hyg. Abt. 1 Orig. Reihe A 268:34-39.

57. Scott, M. 1968. The pathogenicity of Aeromonas salmonicida (Griffin) in sea and brackish water. J. Gen. Microbiol. 50:864-868.

58. Smibert, R. M., and N. R. Krieg. 1981. General characterization, p. $409-443$. In P. Gerhardt, R. G. E. Murray, R. N. Costilow, E. W. Nester, W. A. Wood, N. R. Krieg, and G. Briggs Phillips (ed.), Manual of methods for general microbiology. American Society for Microbiology, Washington, D.C.

59. Southern, E. M. 1975. Detection of specific sequences among DNA fragments separated by electrophoresis. J. Mol. Biol. 98:503-517. 